We appreciate the response to this publication feature and welcome all contributions. Contributions may be sent to our Technical Editor Phil Oshel, oshel1pe@cmich.edu

\section{Determining the Micron Marker Distance or Magnification of a Microscopic}

\author{
Image \\ Paul Beauregard \\ Chemist and Electron Microscopist, Greensburg, PA \\ beaurega@westol.com
}

Here's how I always calculated and converted between micron marker distances and magnifications on negatives and prints.

\section{General Procedure and Set of Rules:}

1. Take the magnification and convert it to $k \times$. Let's say you get $50 \mathrm{k} \times$.

2. That number in millimeters is the length of ONE micron at that magnification of $50 \mathrm{k} \times$.

3. So in this example, $50 \mathrm{~mm}$ is one micrometer (or $5 \mathrm{~mm}$ is 0.1 $\mu \mathrm{m}$ on higher mag prints). You could try to draw a calibration bar $50 \mathrm{~mm}$ long and label it as $1 \mu \mathrm{m}$, but the print labeling area might not be wide enough for that. What do you do if the distance for one micron is $750 \mathrm{~mm}$ ? In either case, one can use one-tenth of that millimeter distance and label it with a $0.1 \mu \mathrm{m}$ marker bar.

4. Always determine the one micron distance first and then convert up or down from there. This procedure can be used in the reverse order stated and is the more common procedure.

This mag rule works for TEM, SEM, OM, et al. It is easy to remember and it usually does not take a calculator to figure out the mag and micron markers distance changes. Just stick with 1 and 0.1 micron markers. Then all you need to have is a millimeter ruler.

Here's a few examples of how to use this procedure or set of rules. Let's say you see an image in Microscopy Today that shows an internal calibration bar in the image and it says $0.1 \mu \mathrm{m}$. So what is the magnification in MT? Did the author know how much his image would be reduced or enlarged? No. Say the $0.1 \mu \mathrm{m}$ bar is 6 millimeters long. Convert that to a one micron distance and you get 60 millimeters for one micrometer. The mag of the image in MT is $60 \mathrm{k} \times$ regardless of what the labeling under the image says or the article says.

Here's an optical micrograph calculation example. Your print was determined by a stage micrometer calibration to be $37 \times$. That is $0.037 \mathrm{k} \times$ for one micron. Therefore, one micron is $0.037 \mathrm{~mm}$ but you can't draw that length on your photo micrograph. So use $3.7 \mathrm{~mm}$ and label the $3.7 \mathrm{~mm}$ calibration bar as representing 100 microns.

To calibrate an optical microscope magnification, you need a calibration standard called a stage micrometer, which is a highquality ruler with typical lengths from $0.1 \mathrm{~mm}$ to $20 \mathrm{~mm}$ and may have divisions as small as 2 micrometers. Beautifully made NIST traceable step and measurement standards can be purchased from VLSI (vlsistandards.com) for all types of measurements. We used their step standard for quality checking on Mirau interferometry calibrations and setups. The VLSI standards are not cheap but they are certified traceable and ISO9001 certified.

Geller Microanalytical Laboratory Inc. (gellermicro.com) also sells their MRS- 5 standard that is a similar traceable calibration standard and Geller is an ISO-9000 accredited lab. $\mathrm{Mag}^{*}{ }^{*} \mathrm{Cal}$ is a calibration standard for TEM that consists of four sets of five nominally $10 \mathrm{~nm}$ thick $\mathrm{Si}_{0.81} \mathrm{Ge}_{0.19}$ alloy layers, alternating with nominally $13 \mathrm{~nm}$ thick pure silicon layers. The $\mathrm{Si}\{111\}$ lattice planes $(0.03136 \mathrm{~nm})$ layers are imaged in the TEM as are the band thicknesses to establish the calibration. The same procedure can be used to calibrate ALL of the magnifications possible on any microscope: use one of the traceable standards mentioned above to calibrate as many of the magnifications as possible by making images that are rich in larger and smaller features so you can calibrate these additional features. Then make images at any other magnifications that the instrument is capable of where the standard's feature size in too small or large, but include one or more of the additional features that you indirectly calibrated in the previous step. Use these additional feature images to calibrate the magnification of those images where the standard is inappropriate. For example, a high magnification TEM image of a semiconductor device cross section may contain the Si lattice, which can be used to calibrate that magnification. However, that same image may contain integrated circuit layers with thicknesses' ranging from 10's to a hundred $\mathrm{nm}$ or so. These layer thicknesses' can be measured on the image containing the Si lattice and then lower magnification images can be taken to indirectly calibrate these lower magnifications, and so on. Make a table of the instrument magnification readout vs. the actual magnification at that magnification step vs. the percent error at that magnification. It is not uncommon to see errors from $1 \%$ to $5 \%$ or more. Many microscopists still use inexpensive common carbon grating replica (cheaper) for TEM calibration at lower magnifications. For image analysis, you need to photograph a standard, calibrate as above, and "pull" it into your CRT with your software. Then you can calibrate your software directly against your known distance standard. Do both the $x$ and $y$ axis directions.

This mag rule is very helpful and easy to use "on the fly". I gave a presentation with a $35 \mathrm{~mm}$ slide of a TEM micrograph displayed onto a large projector screen. Some guy asked, "What is the actual magnification on the screen?" I picked up a meter stick, measured the distance for the $0.1 \mu \mathrm{m}$ calibration bar as $150 \mathrm{~mm}$, multiplied by ten to get the one micron distance, multiplied by 1000 , and I said, "Close to 1.5 million $\times$."

\section{A Very Simple Method for Quickly Making Large Numbers of Measurements on Micrographs}

\author{
Ron Anderson \\ Microscopy Today, Largo, FL \\ microscopytoday@tampabay.rr.com
}

It has been in the back of my mind to write this up for MT since I retired from a certain large computer company. Inasmuch as Paul's article above is a perfect lead-in, there is no time like the present. Our lab supported a semiconductor integrated circuit and a ceramic substrate manufacturing facility. We were continually required to measure circuit line widths on plan-view specimens and layer thicknesses on cross-section specimens for both semiconductor and 